\title{
Recent Developments in Maximum Power Point Tracking Technologies for Photovoltaic Systems
}

\author{
Nevzat Onat \\ Vocational School of Technical Studies, Marmara University, Kadıkoy, 34722 Istanbul, Turkey \\ Correspondence should be addressed to Nevzat Onat, nonat@marmara.edu.tr \\ Received 24 August 2010; Accepted 11 November 2010 \\ Academic Editor: Fahrettin Yakuphanoglu \\ Copyright () 2010 Nevzat Onat. This is an open access article distributed under the Creative Commons Attribution License, which \\ permits unrestricted use, distribution, and reproduction in any medium, provided the original work is properly cited. \\ In photovoltaic (PV) system applications, it is very important to design a system for operating of the solar cells (SCs) under \\ best conditions and highest efficiency. Maximum power point (MPP) varies depending on the angle of sunlight on the surface of \\ the panel and cell temperature. Hence, the operating point of the load is not always MPP of PV system. Therefore, in order to \\ supply reliable energy to the load, PV systems are designed to include more than the required number of modules. The solution \\ to this problem is that switching power converters are used, that is called maximum power point tracker (MPPT). In this study, \\ the various aspects of these algorithms have been analyzed in detail. Classifications, definitions, and basic equations of the most \\ widely used MPPT technologies are given. Moreover, a comparison was made in the conclusion.
}

\section{Introduction}

Photovoltaic (PV) systems have a structure containing solar cells (SCs), connection, protection, and storage components and some additional elements depending on load characteristics. The most important element of these systems, the solar cells, also has distinctive features especially on the initial investment cost and the quality and quantity of other elements. Therefore, in the initial installation stage, it is very important to design for operating of SC under the best conditions and effectively. Switching power converters are used, that is called as maximum power point tracker (MPPT) for the solution of this problem [1]. However, efficient use of a PV panel includes some problems for the following two main reasons.

(1) Because of rotation of the world around the sun and itself ongoing, it may not have a fixed position to receive constant vertical solar radiation continuously. Thereby, PV systems may include some circuits to track the world movements depending on the sun consisting of stepper motor or other devices. These mechanisms are called the mechanical tracking systems and increase the amount of produced PV energy $[2,3]$.
(2) Due to nonlinear I-V curves of PV cells, output power depends on intersection point of load line with this curve. For solar radiation and cell temperature values taken as examples, there are only one point where maximum power is produced. Therefore, operation of the cell at this point is the right option. This process is called as electrical maximum power point tracking or simply MPPT [2].

\section{Photovoltaic Cell and MPP}

Figure 1 shows the equivalent circuit of solar cell. Electrical energy production of cell has been symbolized by current $\left(I_{\mathrm{ph}}\right)$ demanded from voltage-dependent current source. The amount of produced energy is proportional to solar radiation. Because the body of the solar cell semiconductor material is symbolized as a diode, output voltage of PV cell is shown as $V_{\mathrm{pv}}$. Serial resistance $\left(R_{s}\right)$ is equal to the sum of contact and semiconductor material's resistances. Parallel resistance $\left(R_{p}\right)$ is taken as the sum of resistances between thin-film layers and around cells. In the investigations, it is determined that parallel resistance is too large compared with series resistance, and its effect can be neglected. 


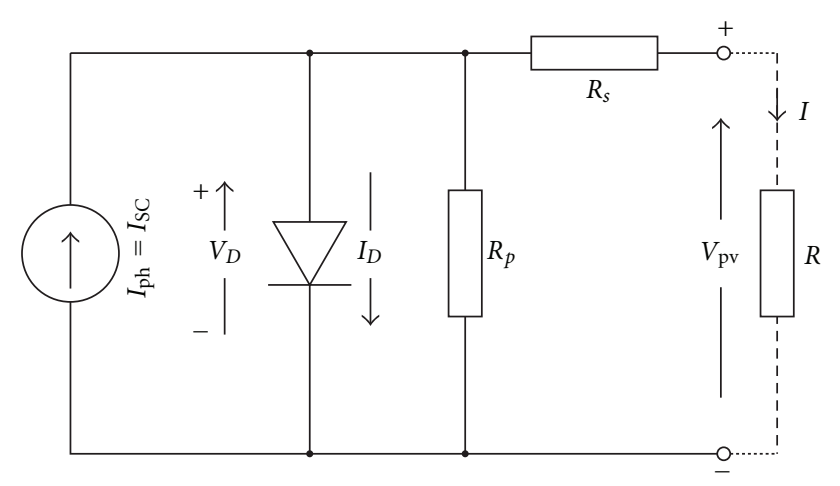

FIGURE 1: Equivalent electrical circuit of an SC.

Therefore, series resistance is assumed as the main resistance of circuit.

As shown in Figure 1, output current of an SC is equal to difference short circuit $\left(I_{\mathrm{SC}}\right)$ current and diode current $\left(I_{D}\right)$. In this case, following equation can be written as

$$
I=I_{\mathrm{ph}}-I_{D}=I_{\mathrm{ph}}-I_{0}\left(e^{(q \cdot V) /\left(k \cdot T_{C}\right)}-1\right) .
$$

Here, $k, T_{C}, q, V$, and $I_{0}$ show the Boltzmann gas constant $\left[k=1.38 \times 10^{-23}(\mathrm{j} / K)\right]$, absolute temperature of SC $[K]$, electron charge $\left[1.6 \times 10^{-19} \mathrm{C}\right]$, voltage across the cell, and the dark saturation current that varies greatly depending on the temperature, respectively. In (1), if the output current assumed as zero, open circuit voltage $\left(V_{\mathrm{OC}}\right)$ is determined as

$$
V_{\mathrm{OC}}=\frac{k \cdot T_{C}}{q} \ln \frac{I_{\mathrm{ph}}+I_{0}}{I_{0}} \approx \frac{k \cdot T_{C}}{q} \ln \frac{I_{\mathrm{ph}}}{I_{0}},
$$

$I_{0}$ can be neglected because of being too small compared with output current $[1,4-6]$.

In Figure 2, current-voltage (I-V) and power-voltage $(\mathrm{P}-\mathrm{V})$ characteristics of a typical SC under variable solar radiation conditions are shown.

As understood from current voltage characteristic, when SC is illuminated, a positive potential occurs at the ends of SC, and an output current can be produced. If a variable resistance $(R)$ is connected as load to the SC Otherwise, when $R$ value is too high, SC will operate between E-F points as a constant voltage source. The most efficient operation point of cell is (A) and called as maximum power point (MPP). Output power $\left(P_{\max }\right)$ and efficiency $\left(\eta_{\max }\right)$ values at this point are equal to

$$
\begin{gathered}
P_{\max }=I_{\text {max }} \cdot V_{\text {max }}, \\
\eta_{\text {max }}=\frac{P_{\text {max }}}{P_{\text {in }}}=\frac{P_{\text {max }}}{\mathrm{A} \cdot G_{a}} .
\end{gathered}
$$

In these equations, $\mathrm{A}$ and $G_{a}$ represent photovoltaic array area $\left[\mathrm{m}^{2}\right]$ and ambient solar radiation in $\mathrm{W} / \mathrm{m}^{2}$, respectively. Another criterion of I-V characteristic is fill factor (FF). FF will also determine the quality of SC. In PV system design,

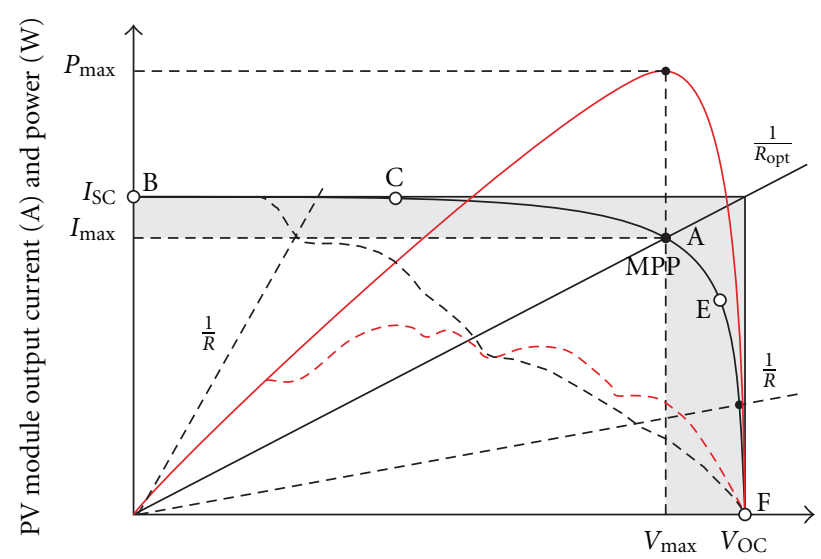

PV module output voltage (V)

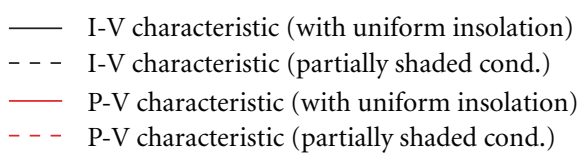

FIgure 2: Characteristics of a typical PV cell $[7,8]$.

FF value of used SC must be 0.7 or greater. Mathematically, FF can be expressed by the following equation [7]:

$$
\mathrm{FF}=\frac{P_{\max }}{V_{\mathrm{OC}} \cdot I_{\mathrm{SC}}}=\frac{V_{\max } \cdot I_{\max }}{V_{\mathrm{OC}} \cdot I_{\mathrm{SC}}} .
$$

MPP, where SC output power reached the maximum value, varies depending on the angle of sunlight on the surface of the panel and cell temperature. Hence, the operating point of the load is not always MPP of PV. Therefore, in order to supply reliable energy to the load, PV systems are designed to include more than required number of modules. In this case, the system cost and the amount of energy loses greatly increase. The solution to this problem is that switching power converters can be used that is called as maximum power point tracker (MPPT). Thus, the continuous operation of photovoltaic panels at MPP can be provided. Generally in uniform conditions (absence of sudden shading or climate changes), using of MPPT is quite considerable increases in output power such as $20 \%-30 \%$ [9]. As shown in Figure 3, MPP varies with solar radiation and a slight cell temperature [10]. In this study, algorithms that are used for determination and tracking of MPP are emphasized. By the investigation of the main principles of the MPPT systems presented in the literature, advantages and disadvantages against each other are analyzed.

\section{Classification of MPPT Algorithms}

The aim of MPPT is to regulate the actual operation voltage of PV panel to the voltage at MPP. For this purpose, MPPT adjusts the output power of inverter or DC converter. If the PV output voltage is higher than MPP voltage, then transferred power to the load or network is increased, otherwise, it is decreased [11]. The main criteria taken into consideration in the selection of MPPT algorithms are summarized below. 


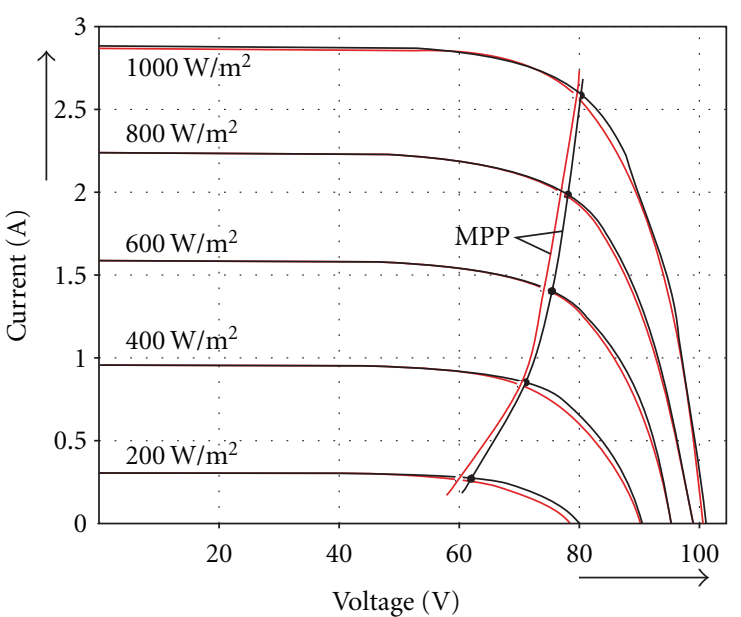

$-40^{\circ} \mathrm{C}$
$-\quad 50^{\circ} \mathrm{C}$

FIGURE 3: Changing of MPP with solar radiation and temperature.

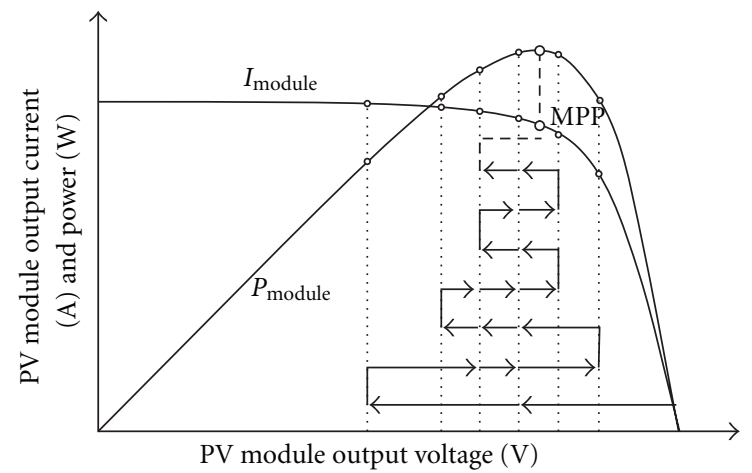

FIGURE 4: Determination of MPP in hill-climbing method.

(i) Ease of Implementation. Some techniques consist of analog circuits and others are digital. Sometimes digital MPPT algorithms may require software and programming.

(ii) The required number of sensors. Voltage measurement is usually easier and more reliable than current. Current sensors are also often expensive and cumbersome structure. The sensors measure the light level are not easy to find. Therefore, these features should be considered in MPPT design stage.

(iii) Due to a partial shading on PV, panels can affect the normal operation of the MPPT. If the selected algorithm is too sensitive, virtually MPPT that occurred by shading may be tracked. As a result of this, significant power losses may arise.

(iv) Determination of the cost of an MPPT algorithm is not easy before implementation. Accurate cost compassion depends on system features such as analog or digital, software and programming requirements, and number of sensors. Generally analog algorithms are cheaper than digital ones. (v) Different MPPT techniques are suitable for different applications. In each system, an algorithm may not give the same result [12].

Efficiency ( $\left.\eta_{\text {MPPT }}\right)$ is the most important parameter of an MPPT algorithm. This value is calculated as

$$
\eta_{\mathrm{MPPT}}=\frac{\int_{0}^{t} P_{\mathrm{MPPT}}(t) d t}{\int_{0}^{t} P_{\max }(t) d t} .
$$

In (5), $P_{\text {MPPT }}$ represents the output power of PV system with MPPT, and $P_{\max }$ is the output power at true maximum power point [13]. It was obtained as a result of experimental studies that MPPT efficiency varies depending on cell temperature and fill factor. According to [14], MPPT efficiency increases with temperature and only FF changing also affects the efficiency around $4 \%$ under constant temperature conditions. MPPT efficiency is associated with climatic conditions and features of geographic region where PV is system located. MPPT used to increase battery charger in PV systems with storage unit; the amount of this increase should be more than the amount the device itself losses. Otherwise, there is not any net income. Theoretical calculation model was developed to analyze benefits of MPPT under different climatic conditions. In an experimental study realized by Chena et al. for that purpose, MPPT algorithm was used in two PV systems located in different regions of China, where they have distinctive climatic conditions. Eventually, it was determined that climate change can cause approximately $10 \%$ of differences between MPPT efficiencies [15]. In the most general sense, MPPT techniques can be grouped under two headings as direct and indirect systems.

3.1. Indirect MPPT Algorithms. Indirect MPPT algorithms operate based on calculation of PV cell voltage at maximum power point using sample measurements and assumptions. There are several application modes of these techniques, and some of them are summarized below.

(i) System voltage (operating voltage of PV panel) can be adjusted seasonally. In this case, depending on cell temperature, it is expected that MPP voltage in winter will be higher than summer.

(ii) Operating voltage can be adjusted according to the temperature of the module.

(iii) MPP voltage can be calculated by multiplying of instantaneous open-circuit voltage of PV cell with a certain constant coefficient (such as, for example, 0.8 for silicon cells). Open-circuit voltage is measured periodically. These measurements are realized by interruption of load for very short times such as $1 \mathrm{~ms}$ every two minutes.

(iv) In some systems, MPPT algorithms are designed according to the azimuth and altitude of the sun. Depending on geographical location of PV system, the change of angle of the sun is transferred to a database. Thus, MPPT movements are formed by information in this database as in [16]. 


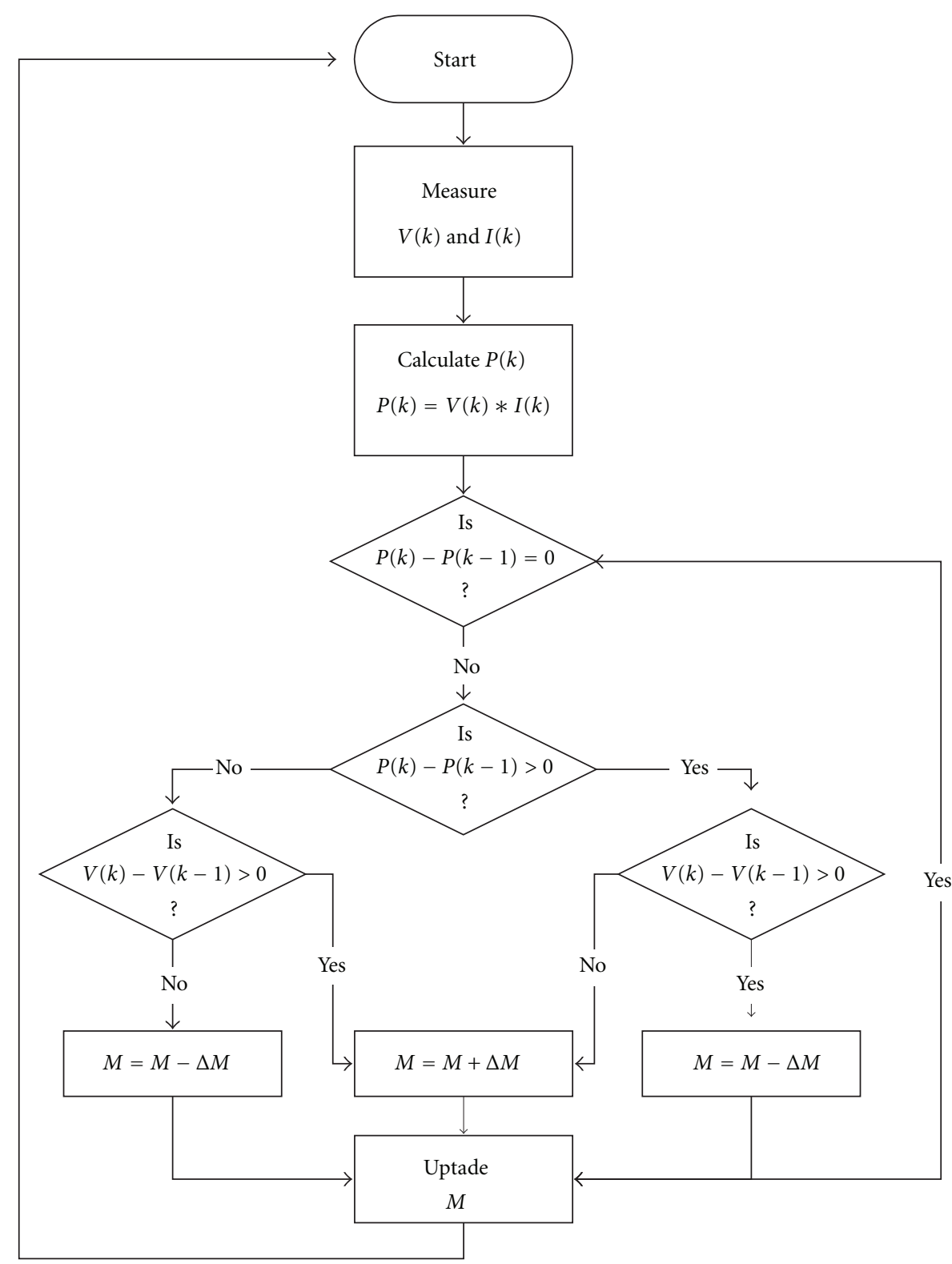

FIGURE 5: Flowchart of hill-climbing MPPT algorithm.

The advantage of the methods described above is their very simple structures, but they only give estimation for optimum operating point. They are not sensitive to changes due to aging and contamination of cells.

3.2. Direct MPPT Algorithms. In these MPPT algorithms, optimal operating point is determined by measurement of PV panel current, voltage, or power. Therefore, these methods affected the performance changes in time due to various reasons and can make a more accurate tracking. These algorithms use the following basic principles.

(i) In MPPT systems operating with the principle of periodic tuning of specific portion of I-V characteristic curve, module's operating voltage is limited by the framework of DC/DC converter voltage. Maximum module power is obtained, and voltage operating point is set to correspond to this power. In practice, it is easier to measure the output current of DC/DC convertor and raise the maximum value. The desired goal would be realized with this method.

(ii) Second method is the most well known and called as hill-climbing algorithm. Here, operating voltage is changed periodically in small steps, and the increase in module power or current is measured. So, increases or the standing start point of decreases is determined and accepted as the instantaneous operating point (Figure 4). If the power or current increases depending on the voltage rising of each step, tracking direction is forward, otherwise it is continued backwards. Maximum power point is determined with this way, and operating point makes an oscillation around real MPP $[17,18]$. 


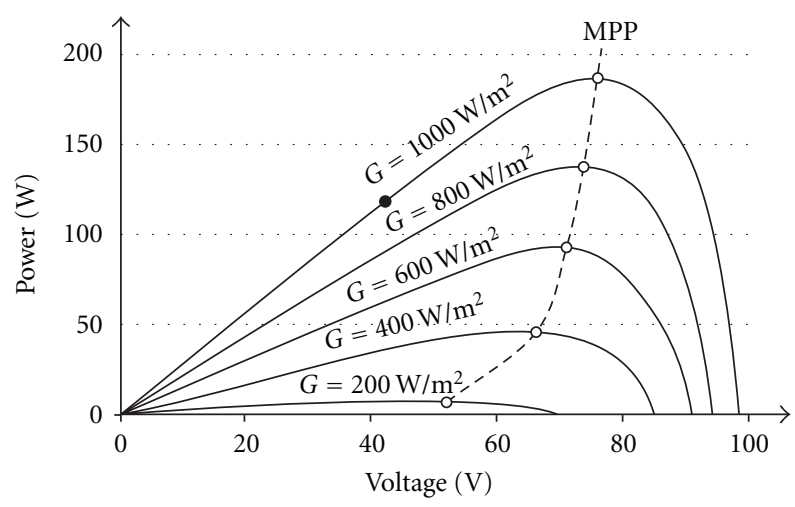

Figure 6: Power-voltage relationship in PV systems.
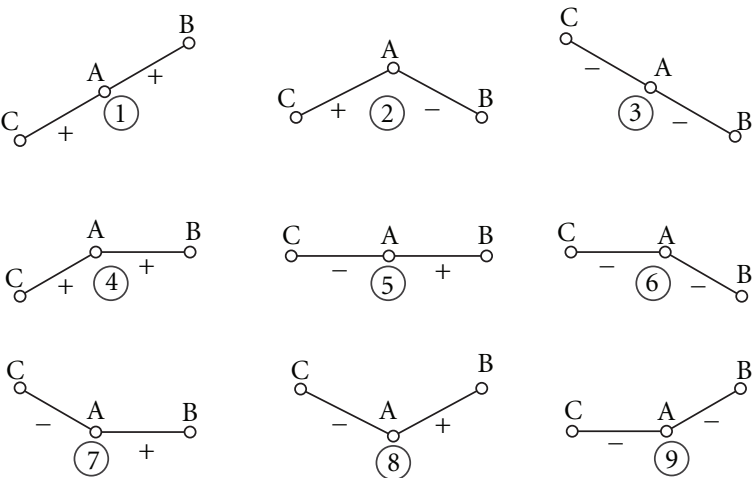

FIgURE 7: Three-point weight comparison situations [26].
Simply, the working regions in Figure 2 can be taken into account to write the mathematical expression of hillclimbing method. If operating point of load is on the left of MPP, in other words if the module works as a current source, (6) can be written as

$$
\frac{\partial P_{\text {module }}}{\partial V_{\text {module }}}<0 \Longrightarrow M=M-\Delta M .
$$

In the opposite case, PV module acts as a voltage source, and error signal $(M)$ is calculated as

$$
\frac{\partial P_{\text {module }}}{\partial V_{\text {module }}}>0 \Longrightarrow M=M+\Delta M \text {. }
$$

At MPP, error will be zero and expression is written as follows:

$$
\frac{\partial P_{\text {module }}}{\partial V_{\text {module }}}=0 \Longrightarrow M=M, \quad \text { or } \Delta M=0 .
$$

Flowchart of hill-climbing algorithm is given in Figure 5 [19].

\section{Definitions of MPPT Algorithms}

Another classification form of MPPT algorithms may be according to the used control techniques. In literature, many control techniques are developed for this purpose. Commercially, the most widely used algorithm is the method called perturb and observe (P\&O) in PV system market. Despite this, the algorithm which gives the best results has occurred in the no consensus. One of the most important reasons for this is also the lack of comprehensive comparative analysis of these algorithms in terms of efficiency. In literature, most of comparative studies are realized between systems that include MPPT and those that do not. Another common analysis method depends on comparison of MPPT algorithm and a convertor designed for certain operating point. MPPT techniques are described below and examined in detail in the light of recent developments.

4.1. Perturb and Observe (PÆO) Algorithm. P\&Q is the most widely used algorithm due to the simplicity of implementation practically. In this method, $\mathrm{P}-\mathrm{V}$ characteristic of PV cell is used. As known, produced power by PV array varies as a function of voltage. In $\mathrm{P} \& \mathrm{O}$ algorithm, a small increase in operating voltage of PV array is realized, and the amount of change in power $(\Delta P)$ is measured. If $\Delta P$-value is positive, operating voltage is increased again to reach MPP, thus, sign of power error track by these small voltage errors. Let us assume that a PV array has P-V characteristic and operates at point $(\mathrm{A})$ as in Figure 6. By repeating the process above, the operating point moved upwards. After MPP, the value of $\Delta P$, the resulting increase in voltage, will be negative. In this case, the direction of voltage adjustment is reversed, and operating point (A) in trying to make it is the closest to MPP [20]. Today, $\mathrm{P} \& \mathrm{O}$ algorithm typically includes digital and computer-controlled applications. However, applications of analog circuits are also possible, and testing results are very successful as in [21].

The main advantages of $\mathrm{P} \& \mathrm{O}$ algorithm are simple structure and ease of implementation, with both stand-alone and grid-connected systems, MPP tracking can be done with very high efficiency $[22,23]$. But it has limitations that reduce efficiency of MPPT. In the lower solar radiation cases, such as $G=400 \mathrm{~W} / \mathrm{m}^{2}$ and $G=200 \mathrm{~W} / \mathrm{m}^{2}$ curves in Figure 6 , because of becoming smooth, it is difficult to determine the location of MPP exactly. In this situation, voltage changes generate very small power errors. Therefore, MPPT efficiency reduces. Another disadvantage of $\mathrm{P} \& \mathrm{O}$ method is also that it cannot determine actual location of MPP. In this method, only the oscillation of point (A) can be achieved in a region close to MPP. In order to reduce the amount of these oscillations, some studies have been conducted in the literature, for instance, the time intervals between voltage movements can be increased by adding a waiting period $[24,25]$. However, this application is successful under the constant or linear solar radiation conditions. Even under these conditions, it may also increase the efficiency of the algorithm. But additional standby time slowdowns the response time of the change in atmospheric conditions and worsens the unstable behaviors especially in partially clouded days. Another method of reducing oscillations is called the three-point weight comparisons (TPWCs). TPWC method is a modified version of $\mathrm{P} \& \mathrm{O}$ algorithm. This algorithm is based on comparisons between voltage (or current) and power of PV array. In application, primarily the power $\left(P_{1}\right)$ 


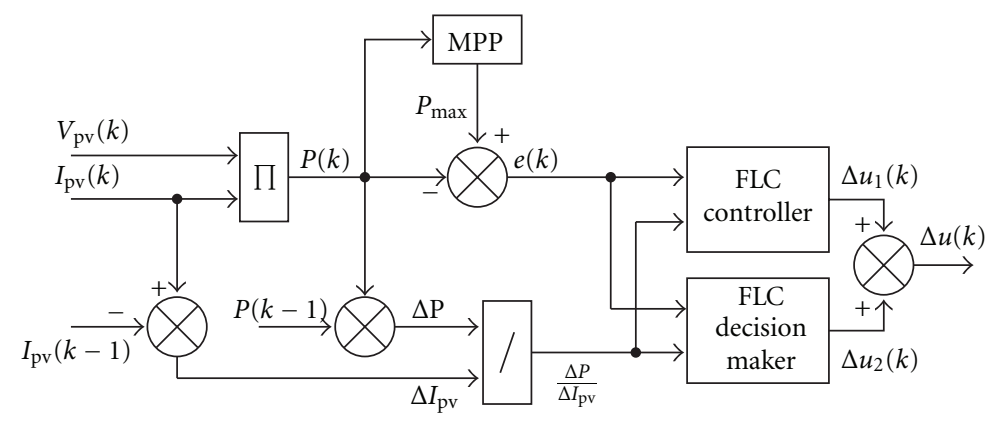

(a)

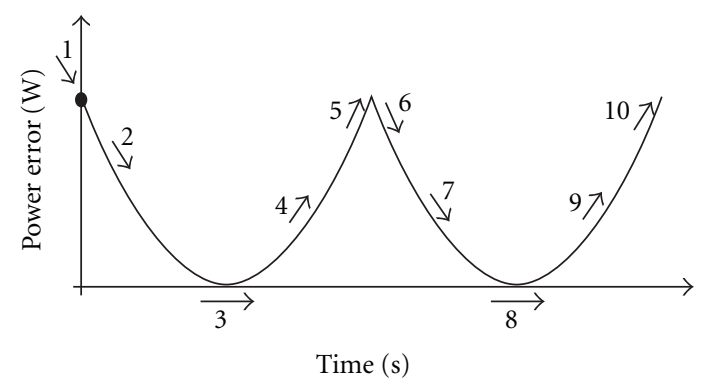

(b)

FIgURE 8: (a) Block diagram of dual FL MPPT algorithm and (b) power error changing of PV cells with time [35].

at $V_{1}$ array voltage and $P_{2}$ value that occurred by increasing of voltage to $V_{2}$ are measured. After this procedure, voltage is decreased to $V_{1}$ again and determined the power $\left(P_{1}^{\prime}\right)$ at this point. If the difference between the values of $P_{1}$ and $P_{1}^{\prime}$ occurs, it is concluded that this is the change in the amount of radiation in the environment and the process is repeated. If the difference is not panel's operating point, it is unchanged. As shown in Figure 7, three different situations may arise in this method. Basically, if $\mathrm{B} \geq \mathrm{A}$ or $\mathrm{C}<\mathrm{A}$, this situation is assumed to be positive. In case of $\mathrm{B}<\mathrm{A}$ or $\mathrm{C} \geq \mathrm{A}$, the situation is called negative [26]. The main disadvantages of this method are the decrease in operating speed and increasing complexity depending on sampling number $[10,27]$.

Another study to reduce the oscillations of $\mathrm{P} \& \mathrm{O}$ algorithm is realized by Chen et al. in 2010. In this paper, an MPPT algorithm is presented that has biological swarm chasing procedure. In order to determine the direction of tracking accurately, a system is suggested that assume all modules of PV array associated with each other. Consequently, each module is a separate part of the system, and samples are taken from all of them. In this algorithm, MPP is seen as a movement goal. Thus, each module automatically is a chain in the determination of MPP. This method has provided a higher efficiency at a rate of $12.19 \%$ then classical $\mathrm{P} \& \mathrm{O}$ algorithm [28].

4.2. Artificial Intelligence-Based MPPT Algorithms. In recent years, fuzzy logic (FL), artificial neural networks (ANNs), and genetic algorithm (GA) techniques known as artificial intelligence techniques have been used widely in the MPPT process. Especially under nonuniform and partially shading conditions, power and current characteristics of PV cells are more complex (as shown in Figure 2), and it is also more difficult to track MPP. Therefore, for a satisfactory result, all environmental conditions (especially instantaneous climate changes and partially shading) must be taken into account in the design process of MPPT. Artificial intelligence can produce appropriate solutions for these conditions.

Syafaruddin et al. showed an efficient MPPT algorithm developed under nonuniform conditions that are based on a trained ANN, according to the occurring temperature and solar radiation changes in partial shade situations. In the proposed method, an FL block uses the error signals generated by ANN [29]. D'Souza et al. and Ammasai et al. explained the drawbacks of fixed step size of conventional $\mathrm{P} \& \mathrm{O}$ systems and a modified MPPT algorithm suggested that the use of FL and no-switching region schemes has improved steady-state performance by using of variable error size $[30,31]$.

Karlis et al. have also presented a new MPPT algorithm that uses fuzzy cognitive networks (FCNs). Actually, FCN is an extension model of well-known fuzzy cognitive maps (FCMs). FCN can also model time-varying dynamic complex systems according to nonlinear rules. In application, FCNs consist of nodes that represent system characteristics and possible controller movements. In addition, FCNs constantly interact with the physical system and send signals to control movement and feedback from the system. Thus, FCNs collect accumulated knowledge and experience in the operation of the system. FCN nodes define the control and actual operating variables (voltage, current, radiation, and temperature). Connections between nodes obtained data 


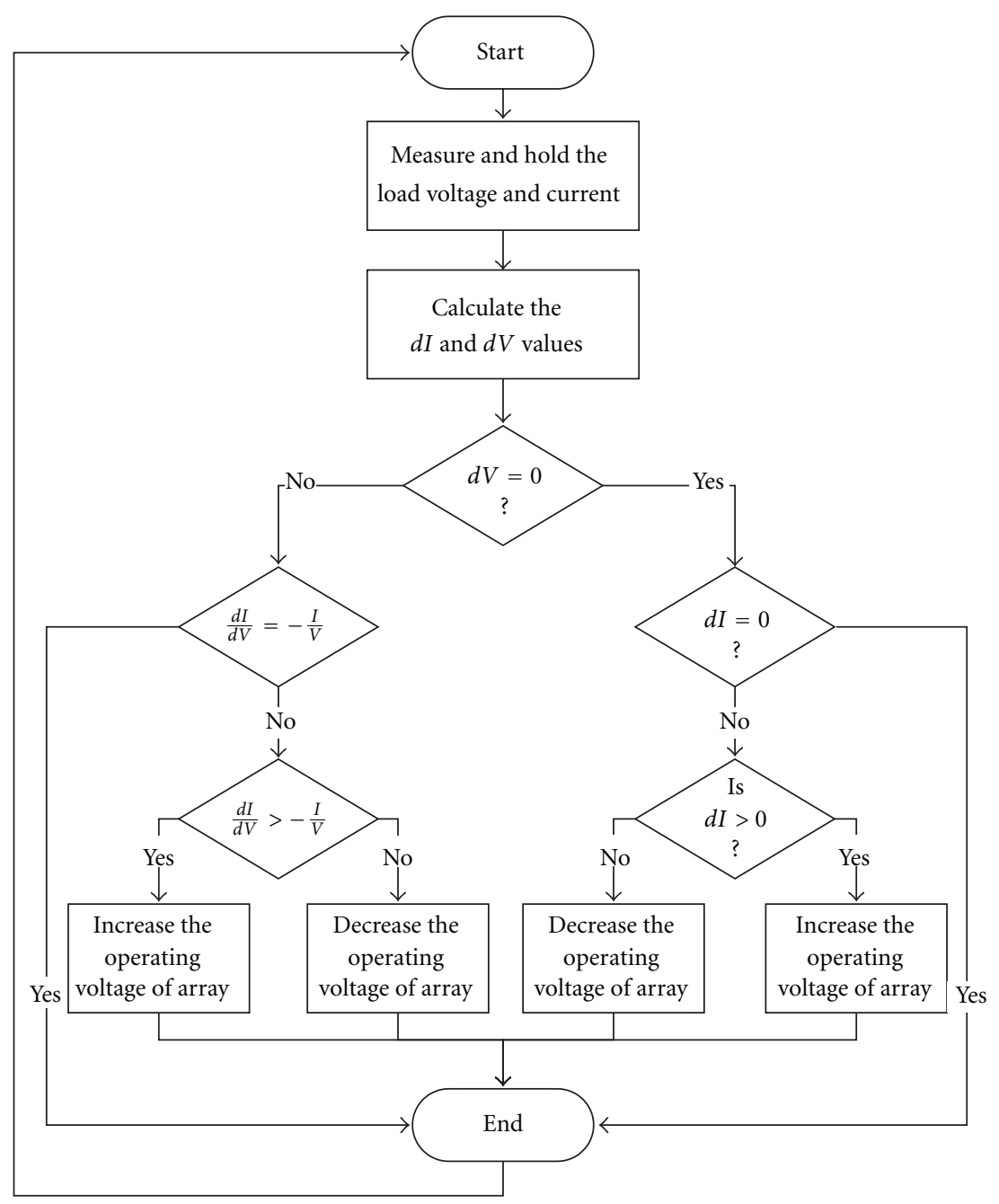

FIGURE 9: Flowchart of IC algorithms for MPPT [10].

that used to describe behaviors of system under nonuniform climatic conditions varying in a wide range. Finally, it is determined that energy loss of this method is less than conventional P\&O method. The annual amount of errors was measured as $6.609 \%$ in $\mathrm{P} \& \mathrm{O}$ method. This value is calculated as $2.01 \%$ for suggested FCN method [32]. In a study conducted by Larbes et al., GA algorithm was used in order to increase the operating speed in the creation of the rule table of fuzzy logic-based MPPT [33]. In a similar study, speed reductions in implementation of $\mathrm{P} \& \mathrm{O}$ algorithm and particularly common disadvantages are listed in a sudden change. It is indicated that Adaptive Fuzzy and ANFIS-based MPPT algorithms have better performance. However, the disadvantages of being more complex and requiring features such as high-performance controllers are considered. In order to increase the performance of conventional fuzzy systems, it is featured that genetic algorithms and particle swarm optimization techniques have been widely used in recent years [34].

Another MPPT algorithm with double FL controller is proposed by Altas and Sharaf in [35]. In that study, rule tables of FL controller are formed according to operating regions given in Figure 8. In startup time, panel current is zero and voltage is equal to open-circuit value. Hence, the power is also zero. This situation causes major power failures in 1st operating region in Figure 8(b).

This major error is slightly decreased in the region 2. If the operating point is equal to maximum power, this error will be zero as at the region 3 . If the load current continues to increase, due to overload, output power will be reduced and shifted to the 4 th region. If some load is not deactivated, operating point reaches to 5 th region. So the power falls to zero, and a short circuit condition occurs. By the outage of some load, the power will increase again, and operating point shifts from the 6 th region to regions 7 and 8 . 8th and $3 \mathrm{rd}$ regions are equal to each other in terms of MPP and are ideal operating regions. Hence, PV cell must operate at these regions by the accurate switching of loads and batteries. In light of this information, 10 operating areas are determined and the rule table is formed accordingly [35].

Wang et al. compared the two MPPT algorithms with FL and the above-mentioned TPWC. According to the 
TABLE 1: Comparison of MPPT techniques according to several parameters $[10,28,32,36]$.

\begin{tabular}{|c|c|c|c|c|c|c|}
\hline \multirow[b]{2}{*}{ Comparison parameters } & \multicolumn{6}{|c|}{ MPPT Algorithms } \\
\hline & $\begin{array}{l}\text { Perturb \& } \\
\text { observe }\end{array}$ & Modified P\&O & $\begin{array}{c}\text { Artificial } \\
\text { intelligence }\end{array}$ & $\begin{array}{c}\text { Constant } \\
\text { voltage } \\
\text { (current) }\end{array}$ & $\begin{array}{l}\text { Incremental } \\
\text { conductance }\end{array}$ & $\begin{array}{l}\text { Parasitic } \\
\text { capacity }\end{array}$ \\
\hline Efficiency (\%) & $81.5-85$ & $93-96$ & $>95$ & $88-89.9$ & $73-85$ & 99.8 \\
\hline $\begin{array}{l}\text { PV Panel depending } \\
\text { operation }\end{array}$ & No & No & Yes & Yes & No & No \\
\hline $\begin{array}{l}\text { Exactly MPP } \\
\text { determination }\end{array}$ & Yes & Yes & Yes & No & Yes & Yes \\
\hline Analog or digital control & Both & Digital & Both & Analog & Digital & Analog \\
\hline $\begin{array}{l}\text { Periodic tuning } \\
\text { requirement }\end{array}$ & No & No & No & Yes & No & No \\
\hline Convergence speed & Varies & Fast & Fast & Medium & Varies & Fast \\
\hline Complexity & Low & Medium & High & Low & Medium & Low \\
\hline Measured parameters & Voltage, current & Voltage, current & Varies & $\begin{array}{l}\text { Voltage } \\
\text { (current) }\end{array}$ & Voltage, current & Voltage, current \\
\hline
\end{tabular}

simulation results, FL-based algorithm operates with $3.07 \mathrm{~W}$ power loses of total $230 \mathrm{~W}$. These loses reduce by increasing of solar radiation to $0.42 \mathrm{~W}$. The average error is around $1.5 \mathrm{~W}$, and this value is a significantly successful value for a $230 \mathrm{~W}$ system. In TPWC algorithm, average loses are under $1.5 \mathrm{~W}$. But instability of this method is higher especially in low solar radiation situation especially in the morning and evening hours. Eventually, both choices are deemed equally [26].

4.3. Constant Voltage (or Current) Algorithms. Constant voltage (CV) algorithm is based on approximately constant ration between voltage of MPP $\left(V_{\max }\right)$ and open-circuit voltage as given in the following equation:

$$
\frac{V_{\max }}{V_{\mathrm{OC}}} \cong K<1
$$

In this algorithm, solar panel is temporarily separated from MPPT, and open-circuit voltage is measured. Later, voltage at MPP is calculated by using (9). By the adjusting of array voltage to this calculated value, the operation at MPP is achieved. This process is repeated periodically and the position of MPP is tracked continuously. Although this method is quite simple, it is difficult to determine the optimal value of constant $K$. In literature, $K$ value was revealed to be between $73 \%$ and $80 \%$ [10].

Constant voltage control can be performed easily with analog equipments. However, MPP tracking efficiency of this method is lower than other algorithms. The reasons for this are the difficulty of obtaining the optimal value of constant $K$ mentioned earlier and even more important requirement of sudden interruption of PV power to measure open-circuit voltage.

MPPT algorithm is presented in different properties by $\mathrm{Hu}$ et al., who use the $\mathrm{CV}$ algorithm as driving element at startup time. This algorithm is based on numerical calculation and quadratic interpolation methods. Instantaneous voltage value of the system is calculated exactly. So the next tracking step is applied based on this value. In the startup period, CV methods are used to determine the opencircuit voltage. In conclusion, rapid and efficient tracking is provided by using of hybrid operation [37].

The above approach to CV algorithm can also be realized in the same way for constant current (CC) method. In this method, (9) is modified as

$$
\frac{I_{\max }}{I_{\mathrm{SC}}} \cong K<1
$$

As shown in (10), the ratio between currents of MPP and short circuit is controlled in CC algorithm. In application process, a switch is used that is located in PV array terminals or input of convertor to create a sudden short circuit by switching on it. In this case, short circuit current is measured, and current value of operating point is determined using of constant $K$. Naturally, the constant voltage method is preferable. Voltage measurement is a more simple process than current. In addition, the cutting of voltage is easier than the current. To short circuit, the array terminals may not often be possible practical [10].

4.4. Incremental Conductance Algorithm. Incremental conductance (IC) algorithm is based on that the derivative of PV power by the voltage is equal to zero. Accordingly, at the maximum power point,

$$
\frac{d P}{d V}=\frac{d(V \cdot I)}{d V}=I+V \frac{d I}{d V}=0 .
$$

By rearranging of (11), the following equation is obtained:

$$
-\frac{I}{V}=\frac{d I}{d V} .
$$

$-I / V$ value in (12) is the inverse of the instantaneous conductance [38]. The expression on the right side of the 
equation is incremental conductance. In this case, these two values must be equal but opposite sign at the maximum power point. In the case of an inequality of this equation, it is understood that operating voltage is lower or higher than MPP voltage. Flowchart of IC method is shown in Figure 9.

IC method as different from $\mathrm{P} \& \mathrm{O}$ algorithm can determine in which direction it has to do voltage changing. Therefore, IC method does not track in the wrong direction even under rapidly changing conditions. In addition, this method can also calculate reached or not to MPPT exactly. Thus, oscillation problem of $\mathrm{P} \& \mathrm{O}$ algorithm around MPP would have been eliminated. In uniform conditions, there is no significant difference between the efficiencies of these two methods $[10,36]$. In literature, IC method was determined to operate with more efficiency under randomly generated conditions [39]. However, the cost of IC method is high due to requirements of high sampling compliance and speed control as a result of complex structure [11]. Classically, $\mathrm{P} \& \mathrm{O}$ and IC methods that are the most widely used techniques of hillclimbing algorithm have two major disadvantages. In these methods, decision-making speed increases in proportion to the step size of error. However, higher error step size reduces the efficiency of MPPT. The second major problem is the direction errors under rapid atmospheric changes especially in $\mathrm{P} \& \mathrm{O}$ algorithm [40].

4.5. Parasitic Capacity Algorithm. Parasitic capacity (PC) method shows similarities with the IC method. However, changing of parasitic junction capacity (PJC) value is taken into account in this method. PJC occurs as result of charge accumulation in $p-n$ junction area and the inductance associated to the connections of PV cells. Actually, there are two main components (parasitic capacitance and inductance) called the reactive parasitic components. It is determined that the parasitic capacitance reduces the error signal when the PV panel is operating outside the MPP, slowing down the system dynamic [41]. But these unavoidable losses are used as an important parameter in determining the MPP. By adding the current $(i(t)=C(d V / d t))$ demanded by this capacity to (1), the following equation is obtained:

$$
I=I_{\mathrm{ph}}-I_{0}\left(e^{(q \cdot V) /\left(k \cdot T_{C}\right)}-1\right)+C \frac{d v}{d t}=F(v)+C \frac{d v}{d t} .
$$

Derivative of multiplying this equation by the panel voltage, (14) can be written as

$$
\frac{d F(v)}{d v}+C\left(\frac{V^{\prime}}{V}+\frac{V^{\prime \prime}}{V^{\prime}}\right)+\frac{F(v)}{v}=0 .
$$

Three terms in this expression represent the instantaneous conductance, voltage oscillations due to parasitic capacities, and incremental conductance, respectively. Firstand second-order derivatives of array voltage have taken the A.C. ripple components into account. If the capacity value is assumed as zero in (14), the equation of IC algorithm is obtained. Parasitic capacity is modeled as a capacitor that is parallel connected to each cell in a PV module. Therefore, parallel connection of modules increases the amount of parasitic capacity for MPPT. As a result of this, the efficiency of PC method is reached to maximum value in highpower PV systems that include numerous parallel-connected modules [10].

\section{Conclusions}

MPPT algorithms used in PV systems are one of the most important factors affecting the electrical efficiency of system. As a result of cost optimization, after decided to use an MPPT system by the designer, it is important to decide which algorithm will be used in application.

In this study, general classification and descriptions of the most widely used MPPT algorithms are analyzed in detail. Operating principles and application processes of MPPT algorithms such as perturb and observe, constant voltage and current, incremental conductance, parasitic capacity, threepoint weight comparison, and artificial intelligence have been discussed. As results of analysis, obtained efficiency ranges and other criteria for comparison are given in Table 1. As shown, different benefits may be selection reason for each algorithm. Parasitic capacity, modified P\&O, and artificial intelligence-based MPPT algorithms are the most advantageous systems in terms of electrical efficiency. However, in practice, the most widely used commercial designs are $\mathrm{P} \& \mathrm{O}$ and IC algorithms due to their simple structures and low cost. Recently, the using areas of software-based artificial intelligent techniques such as FL, ANN, and GA are growing in MPTT applications. As noted above, varied MPPT techniques are suitable for different applications. In each system, an algorithm may not give the same result.

\section{References}

[1] A. Balouktsis, T. D. Karapantsios, K. Anastasiou, A. Antoniadis, and I. Balouktsis, "Load matching in a direct-coupled photovoltaic system-application to Thevenin's equivalent loads," International Journal of Photoenergy, vol. 2006, Article ID 27274, 7 pages, 2006.

[2] F. R. Rubio, M. G. Ortega, F. Gordillo, and M. López-Martínez, "Application of new control strategy for sun tracking," Energy Conversion and Management, vol. 48, no. 7, pp. 2174-2184, 2007.

[3] S. Jain and V. Agarwal, "New current control based MPPT technique for single stage grid connected PV systems," Energy Conversion and Management, vol. 48, no. 2, pp. 625-644, 2007.

[4] M. R. Patel, Wind and Solar Power Systems, CRC Press, Boca Raton, Fla, USA, 1999.

[5] M. A. Green, "Photovoltaics: technology overview," Energy Policy, vol. 28, no. 14, pp. 989-998, 2000.

[6] R. Messenger and J. Ventre, Photovoltaic System Engineering, CRC Press, Boca Raton, Fla, USA, 2000.

[7] A. D. Hansen, P. Sorensen, L. H. Hansen, and H. Bindner, Models for a Stand-Alone PV System, Danka Services International A/S, 2001.

[8] H. Patel and V. Agarwal, "Maximum power point tracking scheme for PV systems operating under partially shaded conditions," IEEE Transactions on Industrial Electronics, vol. 55, no. 4, pp. 1689-1698, 2008.

[9] E. Karatepe, T. Hiyama, M. Boztepe, and M. Çolak, "Voltage based power compensation system for photovoltaic generation 
system under partially shaded insolation conditions," Energy Conversion and Management, vol. 49, no. 8, pp. 2307-2316, 2008.

[10] D. P. Hohm and M. E. Ropp, "Comparative study of maximum power point tracking algorithms," Progress in Photovoltaics: Research and Applications, vol. 11, no. 1, pp. 47-62, 2003.

[11] W. Libo, Z. Zhengming, and L. Jianzheng, "A single-stage three-phase grid-connected photovoltaic system with modified MPPT method and reactive power compensation," IEEE Transactions on Energy Conversion, vol. 22, no. 4, pp. 881-886, 2007.

[12] L. Piegari and R. Rizzo, "Adaptive perturb and observe algorithm for photovoltaic maximum power point tracking," IET Renewable Power Generation, vol. 4, no. 4, pp. 317-328, 2010.

[13] V. Salas, M. Alonso-Abellá, F. Chenlo, and E. Olías, "Analysis of the maximum power point tracking in the photovoltaic grid inverters of 5 kW," Renewable Energy, vol. 34, no. 11, pp. 23662372, 2009.

[14] N. A. Azli, Z. Salam, A. Jusoh, M. Facta, B. C. Lim, and S. Hossain, "Effect of fill factor on the MPPT performance of a grid-connected inverter under Malaysian conditions," in Proceedings of the 2nd IEEE International Power and Energy Conference (PECon '08), pp. 460-462, Malaysia, December 2008.

[15] W. Chen, H. Shen, B. Shu, H. Qin, and T. Deng, "Evaluation of performance of MPPT devices in PV systems with storage batteries," Renewable Energy, vol. 32, no. 9, pp. 1611-1622, 2007.

[16] C. Sungur, "Multi-axes sun-tracking system with PLC control for photovoltaic panels in Turkey," Renewable Energy, vol. 34, no. 4, pp. 1119-1125, 2009.

[17] J. Schmid and H. Schmidt, "Power conditioning for photovoltaic power systems," in Handbook of Photovoltaic Science and Engineering, A. Luque and S. Hegedus, Eds., pp. 871-873, John Wiley \& Sons, New York, NY, USA, 2003.

[18] T. Tafticht, K. Agbossou, M. L. Doumbia, and A. Chériti, "An improved maximum power point tracking method for photovoltaic systems," Renewable Energy, vol. 33, no. 7, pp. 1508-1516, 2008.

[19] S. Jain and V. Agarwal, "Comparison of the performance of maximum power point tracking schemes applied to singlestage grid-connected photovoltaic systems," IET Electric Power Applications, vol. 1, no. 5, pp. 753-762, 2007.

[20] A. Yafaoui, B. Wu, and R. Cheung, "Implementation of maximum power point tracking algorithm for residential photovoltaic systems," in Proceedings of the 2nd Canadian Solar Building Conference, 2007.

[21] J. M. Enrique, J. M. Andújar, and M. A. Bohórquez, "A reliable, fast and low cost maximum power point tracker for photovoltaic applications," Solar Energy, vol. 84, no. 1, pp. 7989, 2010.

[22] F. Liu, Y. Kang, Y. Zhang, and S. Duan, "Comparison of $\mathrm{P} \& \mathrm{O}$ and hill climbing MPPT methods for grid-connected PV converter," in Proceedings of the 3rd IEEE Conference on Industrial Electronics and Applications (ICIEA '08), pp. 804807, Singapore, June 2008.

[23] J. M. Kwon, B. H. Kwon, and K. H. Nam, "Grid-connected photovoltaic multistring PCS with PV current variation reduction control," IEEE Transactions on Industrial Electronics, vol. 56, no. 11, pp. 4381-4388, 2009.

[24] K. H. Chao and C. J. Li, "An intelligent maximum power point tracking method based on extension theory for PV systems,"
Expert Systems with Applications, vol. 37, no. 2, pp. 1050-1055, 2010.

[25] N. Femia, G. Petrone, G. Spagnuolo, and M. Vitelli, "A technique for improving P\&amp;O MPPT performances of double-stage grid-connected photovoltaic systems," IEEE Transactions on Industrial Electronics, vol. 56, no. 11, pp. 44734482, 2009.

[26] C.-C. Wang, M.-C. Wu, S.-Y. Ou, K.-J. Lin, and C.-R. Lin, "Analysis and research on maximum power point tracking of photovoltaic array with Fuzzy Logic Control and Three-point Weight Comparison Method," Science China Technological Sciences, vol. 53, no. 8, pp. 2183-2189, 2010.

[27] F. Ansari, A. Iqbal, S. Chatterji, and A. Afzal, "Control of MPPT for photovoltaic systems using advanced algorithm EPP," in Proceedings of the International Conference on Power Systems (ICPS '09), pp. 1-6, India, December 2009.

[28] L. R. Chen, C. H. Tsai, Y. L. Lin, and Y. S. Lai, "A biological swarm chasing algorithm for tracking the PV maximum power point," IEEE Transactions on Energy Conversion, vol. 25, no. 2, Article ID 5404251, pp. 484-493, 2010.

[29] . Syafaruddin, E. Karatepe, and T. Hiyama, "Artificial neural network-polar coordinated fuzzy controller based maximum power point tracking control under partially shaded conditions," IET Renewable Power Generation, vol. 3, no. 2, pp. 239253, 2009.

[30] N. S. D’Souza, L. A. C. Lopes, and X. Liu, "Comparative study of variable size perturbation and observation maximum power point trackers for PV systems," Electric Power Systems Research, vol. 80, no. 3, pp. 296-305, 2010.

[31] N. A. Gounden, S. Ann Peter, H. Nallandula, and S. Krithiga, "Fuzzy logic controller with MPPT using line-commutated inverter for three-phase grid-connected photovoltaic systems," Renewable Energy, vol. 34, no. 3, pp. 909-915, 2009.

[32] A. D. Karlis, T. L. Kottas, and Y. S. Boutalis, "A novel maximum power point tracking method for PV systems using fuzzy cognitive networks (FCN)," Electric Power Systems Research, vol. 77, no. 3-4, pp. 315-327, 2007.

[33] C. Larbes, S. M. Aït Cheikh, T. Obeidi, and A. Zerguerras, "Genetic algorithms optimized fuzzy logic control for the maximum power point tracking in photovoltaic system," Renewable Energy, vol. 34, no. 10, pp. 2093-2100, 2009.

[34] N. Khaehintung, A. Kunakorn, and P. Sirisuk, "A novel fuzzy logic control technique tuned by particle swarm optimization for maximum power point tracking for a photovoltaic system using a current-mode boost converter with bifurcation control," International Journal of Control, Automation and Systems, vol. 8, no. 2, pp. 289-300, 2010.

[35] I. H. Altas and A. M. Sharaf, "A novel maximum power fuzzy logic controller for photovoltaic solar energy systems," Renewable Energy, vol. 33, no. 3, pp. 388-399, 2008.

[36] T. Esram and P. L. Chapman, "Comparison of photovoltaic array maximum power point tracking techniques," IEEE Transactions on Energy Conversion, vol. 22, no. 2, pp. 439-449, 2007.

[37] J. Hu, J. Zhang, and H. Wu, "A novel MPPT control algorithm based on numerical calculation for PV generation systems," in Proceedings of the 6th IEEE International Power Electronics and Motion Control Conference (IPEMC '09), pp. 2103-2107, Wuhan, China, May 2009.

[38] F. Sarhaddi, S. Farahat, H. Ajam, and A. Behzadmehr, "Exergetic optimization of a solar photovoltaic array," Journal of Thermodynamics, vol. 2009, Article ID 313561, 11 pages, 2009. 
[39] E. Román, R. Alonso, P. Ibañez, S. Elorduizapatarietxe, and D. Goitia, "Intelligent PV module for grid-connected PV systems," IEEE Transactions on Industrial Electronics, vol. 53, no. 4, pp. 1066-1073, 2006.

[40] S. Kazmi, H. Goto, O. Ichiokura, and H. J. Guo, "An improved and very efficient MPPT controller for PV systems subjected to rapidly varying atmospheric conditions and partial shading," in Proceedings of the Power Engineering Conference, pp. 1-6, Adelaide, Australia, September 2009.

[41] G. Spiazzi, S. Buso, and P. Mattavelli, "Analysis of MPPT algorithms for photovoltaic panels based on ripple correlation techniques in presence of parasitic components," in 2009 Brazilian Power Electronics Conference, COBEP2009, pp. 8895, Brazil, October 2009. 


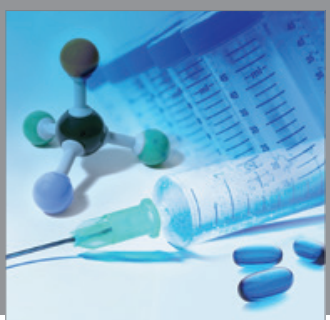

International Journal of

Medicinal Chemistry

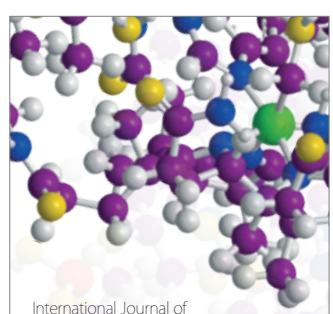

Carbohydrate Chemistry

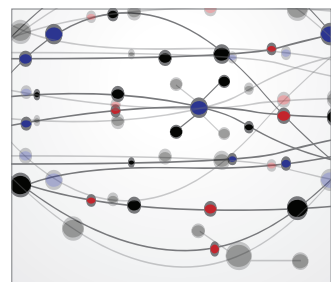

The Scientific World Journal
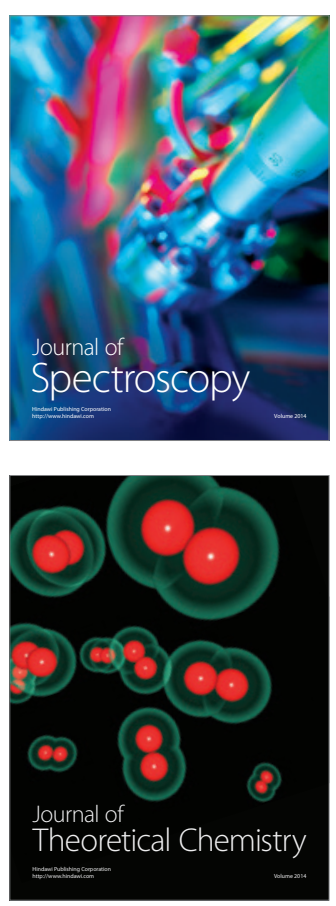
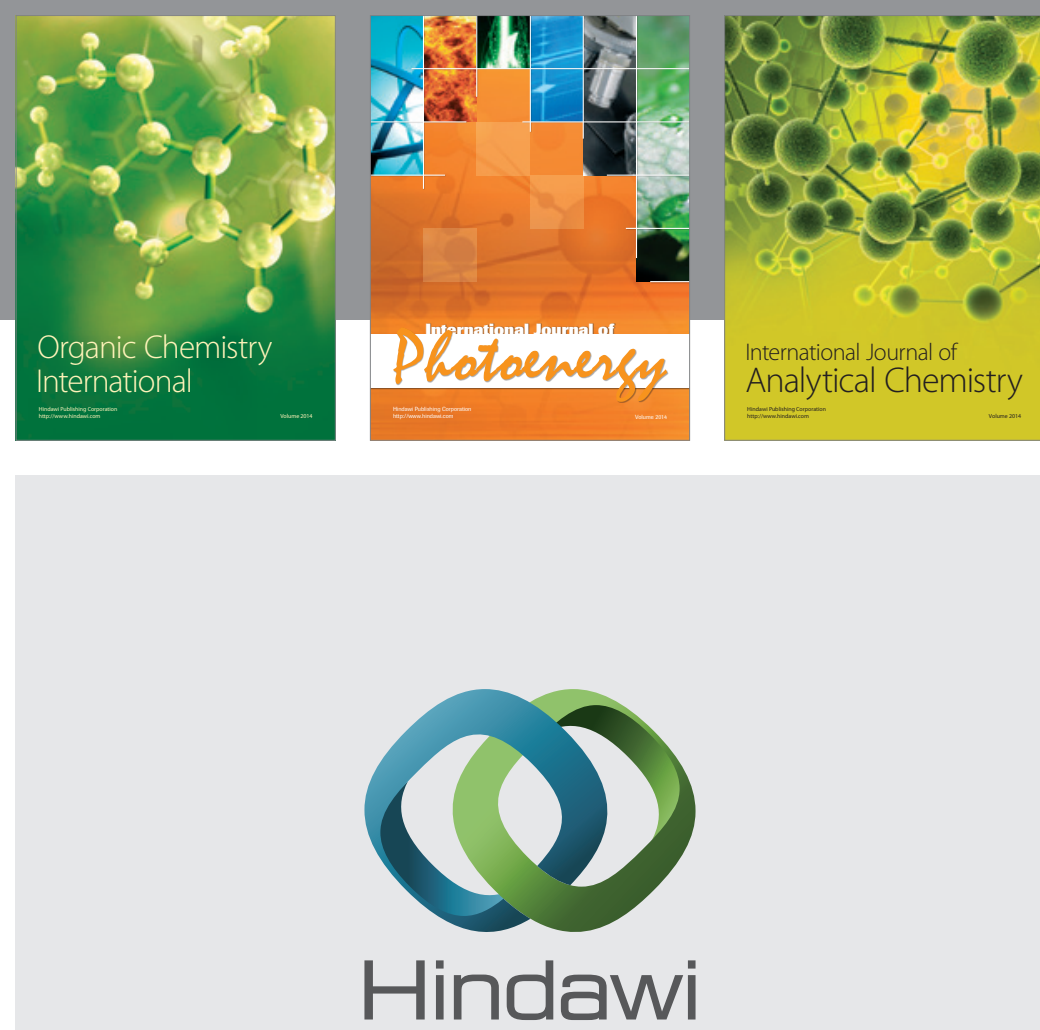

Submit your manuscripts at

http://www.hindawi.com
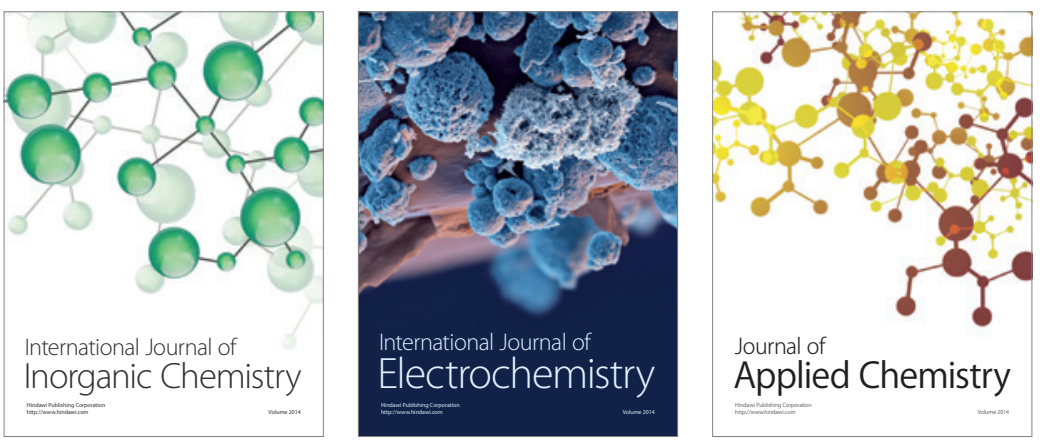

Journal of

Applied Chemistry
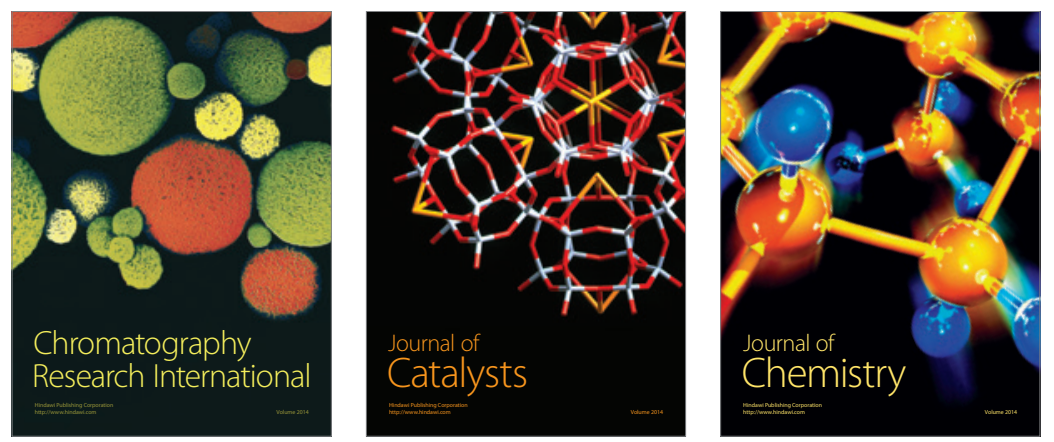
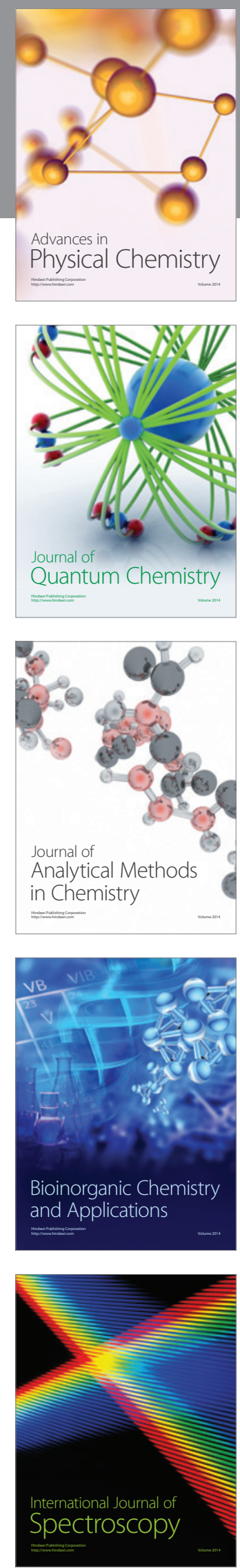